\title{
Women speakers in healthcare: taking steps towards balanced gender representation
}

\author{
Authors: Rose Penfold, ${ }^{A}$ Katie Knight, ${ }^{\mathrm{B}}$ Lucia Magee, ${ }^{\mathrm{C}}$ Greta McLachlan ${ }^{\mathrm{D}}$ and Nada Al-Hadithy ${ }^{\mathrm{E}}$
}

\begin{abstract}
Introduction
International evidence suggests that although the proportion of women speakers at medical conferences has increased during the last decade, women continue to be significantly underrepresented. ${ }^{1}$ Women comprise the majority of the health and social care workforce in the UK, yet occupy approximately $41 \%$ of seats on NHS organisational boards and remain underrepresented in senior leadership positions across the sector. ${ }^{2}$ Conferences offer unrivalled opportunities: to showcase diversity and inclusivity, for networking and as a lever for cultural and organisational change. Female representation at healthcare events is important in the aim to achieve gender equity across the healthcare workforce. Women Speakers in Healthcare (WSH) was co-founded by five NHS healthcare professionals, with a vision to ensure balanced gender representation at all healthcare conferences and events, with parity of opportunity for all.
\end{abstract}

\section{Methods}

WSH is actively promoting and raising the profile of women speakers by creating and maintaining the UK's largest database of women speakers in healthcare, from all backgrounds and professions; providing development and training opportunities to inspire and enable women; and engaging women speakers and male allies through networking and collaboration. Women speakers nominate themselves or others via a speaker nomination form, which automatically pulls through to a secure database. Event organisers contact WSH to request women speakers using a speaker request form; we search the database for women with relevant expertise and experience and seek permission from the speaker(s) identified to facilitate a direct connection via email.

\section{Results and discussion}

At the time of writing and 5 months since its inception, WSH has 418 women speakers signed up to the database, 1,841 Twitter

Authors: Aacademic clinical fellow, Guy's and St Thomas' NHS Foundation Trust, London, UK; ${ }^{\text {P }}$ paediatric emergency medicine consultant, North Middlesex Hospital, London, UK; ' Clinical fellow, NHS Improvement, London, UK; ' ${ }^{2}$ editorial registrar and clinical

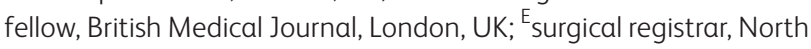
Bristol NHS Trust, Bristol, UK followers, and has facilitated organiser-speaker connections for conferences across a broad range of topics. WSH welcomes all forms of diversity and self-identification and initial data collected during speaker signup indicates that the database is diverse across a wide range of characteristics. WSH's facilitatory role ensures that the model is scalable, and maintains the autonomy and authenticity of speakers, and we believe this approach could be replicated to promote speakers from other underrepresented demographics. We strongly encourage women speakers and supporters to 'lift as we climb', by nominating other women speakers to join the database during the signup process. We are actively engaging with male allies through social media and a 'male allies' database.

Future steps include: To continue to grow the database, to facilitate further speaker-event organiser connections and to organise bespoke development and coaching sessions for women speakers. We request feedback from speakers and conference organisers following every event and intend to analyse this to improve the service and experience offered for both speakers and event organisers. Ultimately, WSH aims to achieve gender balance across all healthcare events. Website: www. womenspeakersinhealthcare.co.uk. Twitter: @womenspeakersHC

\section{Conflicts of interest}

None declared.

\section{References}

1 Ruzycki SM, Fletcher S, Earp M, Bharwani A, Lithgow KC. Trends in the proportion of female speakers at medical conferences in the United States and in Canada, 2007 to 2017. JAMA Netw Open 2019;2:e192103.

2 Sealy R. NHS Women on Boards by 2020. NHS, 2017. www. nhsemployers.org/-/media/Employers/Publications/NHS-WomenonBoards-report.pdf [Accessed 12 September 2019]. 